\title{
INEQUALITIES FOR THE MODIFIED BESSEL FUNCTION OF THE SECOND KIND AND THE KERNEL OF THE KRÄTZEL INTEGRAL TRANSFORMATION
}

\section{ROBERT E. GAUnT}

Abstract. We obtain new inequalities for the modified Bessel function of the second kind $K_{V}$ in terms of the gamma function. These bounds follow as special cases of inequalities that we derive for the kernel of the Krätzel integral transformation.

Mathematics subject classification (2010): 33C10.

Keywords and phrases: Modified Bessel function, Krätzel integral transformation, inequality.

\section{REFERENCES}

[1] Á. BARICZ, Bounds for modified Bessel functions of the first and second kinds, P. Edinburgh Math. Soc. 53 (2010), 575-599.

[2] J. A. BARRios And J. J. Betancor, The Krätzel integral transformation of distributions, Math Nachr. 154 (1991), 11-26.

[3] R. E. GaunT, Inequalities for modified Bessel functions and their integrals, J. Math. Anal. Appl. 420 (2014), 373-386.

[4] W. GAUTSCHI, Some elementary inequalities relating to the gamma and incomplete gamma function, J. Math. Phys. 38 (1959), 77-81.

[5] E. K. IFANTIS AND P. D. SiAfARIKAS, Inequalities involving Bessel and modified Bessel functions, J. Math. Anal. Appl. 147 (1990), 214-227.

[6] E. KRÄTZEL, Eine Verallgemeinerung der Laplace und Meijer transformation, Wiss. Z. Univ. Jena. Math. Naturw. Reihe. 5 (1965), 369-381.

[7] Y. L. LUKE, Inequalities for generalized hypergeometric functions, J. Approx. Theory 5 (1972), $41-$ 65.

[8] F. W. J. Olver, D. W. Lozier, R. F. Boisvert and C. W. Clark (Eds.), NiST Handbook of Mathematical Functions, Cambridge University Press, 2010. 